\title{
Spooky research cuts
}

Two leading researchers in quantum computing have had their funds cut off by a US intelligence-research agency in what seems to be an administrative technicality. The controversy has underscored some scientists' fears that the field in the United States is too dependent on the spy world for funding.

In a letter dated 13 May that was sent to John Holdren, director of the White House Office of Science and Technology Policy, 12 researchers in quantum information science express their concerns about the US government's commitment to the field. The letter focuses on the sudden loss of support from the Intelligence Advanced Research Projects Activity (IARPA), which had previously funded two research teams at the National Institute of Standards and Technology (NIST). The groups are led by physicists David Wineland at NIST's facility in Boulder, Colorado, and William Phillips, a Nobel laureate whose lab is at NIST headquarters in Gaithersburg, Maryland.

Quantum computing has long been of interest to the US intelligence community because of its potential use for code-breaking. And intelligence funding bolstered quantum information science as it was getting going in the 1990s. But "the current approach of the intelligence community does not have a long-term view," says quantum information researcher Christopher Monroe of the University of Maryland in College Park, and it controls "a large fraction of the US effort in this field". The National Science Foundation, the largest single source of civilian government funding for the field, contributes US $\$ 15$ million annually.

In 2007, the newly created IARPA took over funding for quantum information science from the National Security Agency. The following year, IARPA stopped funding the NIST researchers because, it says, it did not want to fund other government agencies.

NIST scientists declined to comment on the issue, deferring questions to IARPA. The intelligence agency confirmed that the funding had stopped, but declined to say how much money had been going to NIST, or the total amount of support for the field. Lisa Porter, IARPA's director, says it has been reviewing all of the projects it inherited. In the case of quantum information science, she says, the NIST funds ran out while managers were reviewing the programme and deciding how NIST might be involved. "Until that role is determined, three NIST researchers who were receiving funds from the legacy efforts are not receiving IARPA funds," Porter says. (A third NIST researcher, Ray Simmonds, lost funding along with Wineland and Phillips.)

Bureaucratic mix-up or not, some researchers argue that the decision weakens the field. "If funding for world-class research groups is altered so abruptly that postdocs must leave, graduate students be dropped, or planned experiments be cancelled, they would quickly deteriorate," says Daniel Kleppner, a physicist at the Massachusetts Institute of Technology in Cambridge, and one of the letter's signatories. "The recent concerns about the proposed funding changes from IARPA arose because there was not enough time to plan for alternative support, and worldclass groups would have been seriously disrupted."

NIST spokesman Ben Stein says that the institute will continue to support the groups: "It's ultimately the responsibility of NIST to make sure these programmes receive the resources they need, and we are committed to ensuring they remain adequately funded."

And Porter argues that IARPA's support for the field is going up, not down, pointing to several new programmes that have been started since the agency was created. "In the aggregate, IARPA anticipates spending about 50-60\% more in fiscal year 2009 than in fiscal year 2008 in the area of quantum information science," she says.

But others say the decision seems to run counter to a report on quantum information science released earlier this year by the National Science and Technology Council, which praised the work and called for a more coordinated strategy to maintain US leadership in the field.

"Anyone who hears about this is shocked beyond belief," says Ivan Deutsch of the University of New Mexico in Albuquerque. "The world leader in quantum computing having funding being terminated based on a technicality seems incredibly shortsighted." Sharon Weinberger 